\title{
Long-lasting dephosphorylation of connexin 43 in acute seizures is regulated by NMDA receptors in the rat cerebral cortex
}

\author{
Z. ZÁDOR ${ }^{1,2}$, R. WEICZNER ${ }^{1}$ and A. MIHÁLY ${ }^{1}$
}

Departments of ${ }^{1}$ Anatomy, and ${ }^{2}$ Neurosurgery, Faculty of Medicine, University of Szeged, Szeged, Hungary

Received March 24, 2008; Accepted May 5, 2008

DOI: 10.3892/mmr_00000019

\begin{abstract}
Gap junctions consisting of connexin 43 subunits provide intercellular communication between astrocytes, contributing to their function of maintaining the central nervous system (CNS) microenvironment. Magnetic resonance imaging (MRI) studies demonstrate prolonged astrocyte swelling related to seizures, while in vitro studies show the disruption of intercellular coupling and the cytotoxic swelling of astrocytes in seizure-equivalent environments. We examined the relation between astrocyte swelling and connexin 43 regulation using an in vivo seizure model. Generalised tonic-clonic convulsions were induced in adult rats using intraperitoneally (i.p.)-administered 4-aminopyridine (4-AP). The expression of connexin 43 mRNA and protein at 1, 3 and $24 \mathrm{~h}$ after seizure induction was measured. Astrocytic swelling was assessed at the same time points using transmission electron microscopy. mRNA and protein levels remained unaltered at all time periods. However, a significant $(\sim 50 \%)$ reduction was found in the amount of phosphorylated (P1, P2) to unphosphorylated (NP) forms of connexin 43 at $3 \mathrm{~h}$. The amount increased thereafter, but was still significantly lower than in the controls at $24 \mathrm{~h}$ postseizure. Simultaneously, marked astrocytic swelling was measured in the neocortex. Pre-treatment with N-methyl-Daspartate (NMDA) receptor antagonist dizocilpine maleate (MK-801) resulted in the amelioration of seizure symptoms and the prevention of connexin 43 dephosphorylation, as well as significantly reduced astrocytic swelling. Dephosphorylation of connexin 43 was shown to reduce astrocytic gap junction (GJ) permeability. Our results therefore suggest that, during acute seizures, a prolonged inhibition of intercellular coupling develops in the astrocyte network. This accounts for the longlasting astrocyte swelling observed, and potentially impairs buffering function. The results also imply that this uncoupling is regulated through neuronal and/or glial NMDA-type glutamate receptors.
\end{abstract}

Correspondence to: Dr Zsolt Zádor, Department of Neurological Surgery, San Francisco General Hospital, 1001 Potrero Ave, Rm 101, San Fransisco, CA 94110, USA

E-mail: zsolt.zador@ucsf.edu

Key words: epilepsy, gap junction, connexin 43, phosphorylation, rat, 4-aminopyridine

\section{Introduction}

Central nervous system (CNS) seizures are characterised by repeated synchronised neuronal bursts, a subsequent increase in transmitter release, and changes in volume transmission and in the diffusion parameters of the extracellular space (1-4). Electric activity and intercellular flow of ions and small molecules are regulated in part by gap junctions (GJs) $(5,6)$. These provide neuronal and glial coupling, and are therefore considered candidates for the pathogenesis of epilepsy (7). Morphological studies have long indicated the presence of GJs between glial cells as well as between neurons (8). GJs are composed of connexin protein subunits that form two hexameric connexon channels on adjacent cell surfaces $(9,10)$. Connexins are encoded by a large multigene family which has more than 20 members in mammals (11). Certain members of this connexin family are cell-specific in their expression; connexin 36 is detected in neurons (12), while connexin 43 is present in astrocytes and in ependyma cells of the CNS (13). The connexon is assembled in the endoplasmic reticulum and the Golgi-apparatus and then inserted into the cell membrane to form an 'unapposed' connexon hemichannel $(10,14)$. This subsequently forms an intercellular GJ with a hemichannel of an adjacent cell (10). The conduction properties of the connexin 43 hemichannels are influenced by the phosphorylation state of the connexin protein subunits; dephosphorylation causes the opening of the hemichannel (15) and decreases the formation of GJs $(15,16)$, resulting in their closure. GJs allow the passive flow of molecules below $1 \mathrm{kDa}(17)$; therefore, the regulation of connexons plays an important role in water-ion homeostasis and volume transmission in the brain in both physiological and pathological conditions (18). Astrocyte cultures and brain slices exposed to seizure-equivalent environments, such as high $\left[\mathrm{K}^{+}\right]_{\mathrm{o}}$ and increased glutamate concentration, displayed delayed dephosphorylation of connexin 43 and decreased coupling of astrocytes (19). The reduction of intercellular coupling impairs the efficient trafficking of ions and metabolites and, as such, is likely to have an impact on glial cell volume in seizures. The long-lasting alteration of extracellular volume transmission [i.e., the significant decrease of the apparent diffusion coefficient (ADC) in several forebrain areas] coupled with the swelling of the astrocytes was measured with magnetic resonance imaging (MRI) combined with electron microscopy in rats during acute 4-aminopyridine (4-AP) convulsions (4). In vitro studies elucidated the mechanisms underlying the initial glial swelling in response to high 
Table I. Experimental groups and animal numbers. ${ }^{a}$

\begin{tabular}{lrcc}
\hline & \multicolumn{3}{c}{ No. animals } \\
\cline { 2 - 4 } $\begin{array}{l}\text { Methods } \\
\text { at 1,3, and 24 h) }\end{array}$ & 4-AP (5mg/kg) & $\begin{array}{c}\text { MK-801 }(1 \mathrm{mg} / \mathrm{kg}) \\
\text { plus 4-AP }(5 \mathrm{mg} / \mathrm{kg})\end{array}$ & $\begin{array}{c}\text { Solvent }(0.9 \% ~ \mathrm{NaCl}) \\
\text { control }\end{array}$ \\
\hline RT-PCR & 9 (3/group) & 9 & 3 \\
Western blot & 15 (5/group) & 15 & 5 \\
Electron microscopy & 9 (3/group) & 9 & 3 \\
\hline
\end{tabular}

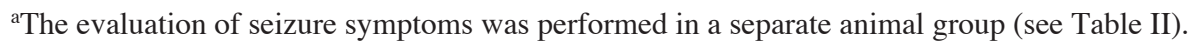

Table II. Behavioural analysis of the effect of NMDA antagonist on 4-AP seizures.

\begin{tabular}{lccc}
\hline Compounds & GTCS latency (min) & SEM & \% animals displaying GTCS \\
\hline 4-AP & 30.3 & 1.4 & 100 \\
4-AP plus MK-801 & 34.2 & 4.5 & $27.7^{\mathrm{a}}$ \\
\hline
\end{tabular}

Tests were conducted in groups of ten animals each. The antagonist was injected intraperitoneally. Ten minutes later, 4-AP was administered, and the latencies of the onset of GTCS were measured from the time of the 4-AP injection (significance, ${ }^{a} \mathrm{p}<0.05$; ANOVA followed by the post hoc Bonferroni test). GTCS, generalised tonic-clonic seizures; SEM, standard error of the mean.

extracellular glutamate $(20)$ and $\left[\mathrm{K}^{+}\right]_{\mathrm{o}}(21)$. Elevated extracellular glutamate levels in seizures are long-lasting - $150 \mathrm{~min}$ or more (22) - but the decrease in ADC values lasts much longer - for at least $24 \mathrm{~h}$ (4). We therefore investigated the role of the neocortical astrocyte network and the possible role of astrocytic GJs in pathological volume regulation in 4-AP seizures. Our present experiments targeted the molecular mechanisms of the regulation of connexin 43 in correlation with the measurable swelling of astrocytes in the neocortex of the convulsing rat. We investigated the role of N-methylD-aspartate (NMDA) glutamate receptors in connexin 43 regulation and edema formation.

\section{Materials and methods}

Animals and treatments. Male Wistar rats weighing 200-250 g were bred in the Central Animal House of the University of Szeged under standard conditions with ad libitum access to food and water. All experiments were conducted in accordance with the European Community Council Directive of November 24, 1986 (86/609/EEC) and the Hungarian Animal Act (1998). Rats were injected intraperitoneally (i.p.) with 4-AP (Sigma, $5 \mathrm{mg} / \mathrm{kg}$ 4-AP dissolved in physiological saline, $1.0 \mathrm{mg} / \mathrm{ml}$ concentration). The control animals received the same volume of physiological saline i.p. Dizocilpine maleate (MK-801, Sigma) dissolved in physiological saline was administered i.p. $10 \mathrm{~min}$ before 4-AP administration at a dose of $1 \mathrm{mg} / \mathrm{kg}$ (23). Animal seizure behaviour was evaluated as previously described by measuring the latency of symptoms (24). Animals were observed at 1, 3 and $24 \mathrm{~h}$ from the time of 4-AP injection, with 3 repeats in each group (Table I). The pharmacological effect of MK-801 was evaluated separately (10-10 animals in each group; Table II).
Nucleic acid measurements. Animals were anesthetised with diethyl-ether, decapitated, their brains removed, and the neocortex of the right hemisphere frozen in liquid nitrogen. For reverse-transcriptase polymerase chain reaction (RT-PCR), the acid guanidinium-phenol-chloroform method (25) was used to extract total-RNA, $2 \mu \mathrm{g}$ of which was used for reverse transcription (RT) (26). PCR was carried out with $1 \mu 1$ of $20 \mu \mathrm{l}$ RT cDNA product along with components, as previously described (27). The sequence of connexin 43 and glycerinealdehyde phosphate dehydrogenase (GAPDH) primers has been previously described $(28,29)$.

After the linearity of connexin 43 and GAPDH was carefully established, PCR was carried out at 17, 22 and 27 cycles. PCR products were separated on $6 \%$ acrylamide gel and stained with ethidium bromide (Sigma). The gels were scanned and the bands evaluated by densitometry using ImageQuant (Typhoon $^{\text {TM }} 9400$ Variable Mode Imager, Molecular Dynamics). The densitometric values of connexin 43 mRNA bands were normalised on GAPDH mRNA detected and amplified from the same samples.

Protein measurements. Neocortex samples were obtained as described above and frozen in liquid nitrogen. Regarding the solubility of the different phosphorylated forms of connexin 43 (9), no detergents were used during protein purification. The second portion of the samples was homogenised in ice cold buffer (pH 7.2) containing $20 \mathrm{mM}$ HEPES, $0.5 \mathrm{mM}$ EDTA and the following protease inhibitors: $1 \mathrm{mM}$ phenylmethylsulfonyl fluoride (PMSF), $1 \mu \mathrm{M}$ pepstatin A and $2 \mu \mathrm{M}$ leupeptin (28). To preserve the phosphorylated forms, $10 \mathrm{mM}$ of the phosphatase inhibitor $\mathrm{Na}_{3} \mathrm{VO}_{4}$ was added to the lysis buffer in specified samples. Homogenates were centrifuged at 20,000 g for $30 \mathrm{~min}$ at $4^{\circ} \mathrm{C}$, then the pellet was resuspended in homogenisation buffer. Alkaline phosphatase treatment was carried 
A

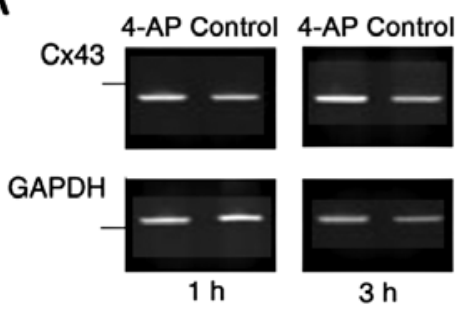

B

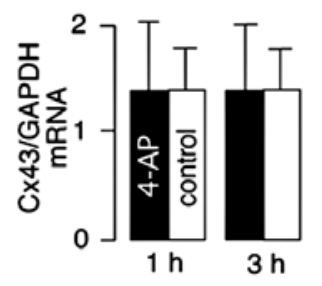

Figure 1. Expression of connexin 43 mRNA following acute 4-aminopyridine (4-AP) seizures. (A) Representative gels exhibiting connexin 43 (Cx43) and the internal control glycerine-aldehyde phosphate dehydrogenase (GAPDH) at 1 and $3 \mathrm{~h}$ following seizure induction. The band indicates $300 \mathrm{bp}$ fragment length. (B) Summarised data. The relative density of the Cx43 bands is expressed as arbitrary units (means \pm STDEV,$n=3$ ).

out with some modifications (30). With $\mathrm{Na}_{3} \mathrm{VO}_{4}$ excluded, $70 \mu \mathrm{g}$ of pre-cleaned lysate was equilibrated against $100 \mathrm{mM}$ Tris ( $\mathrm{pH} 8.0$ ), $100 \mathrm{mM} \mathrm{NaCl}, 5 \mathrm{mM} \mathrm{MgCl}_{2}, 2 \mathrm{mM}$ PMSF and $0.6 \%$ SDS. Half the sample was treated with $2 \mathrm{U} /$ sample alkaline phosphatase at $37^{\circ} \mathrm{C}$ for $4 \mathrm{~h}$, and the other half was incubated untreated. The reaction was terminated by the addition of $200 \mathrm{mM} \mathrm{Na} \mathrm{VO}_{4}$. Samples were re-dissolved in $10 \%$ acrylamide gel with a prolonged run-time $(\sim 2.5 \mathrm{~h}$ at $200 \mathrm{~V}$ ) to separate the different forms of connexin 43 (all chemicals used for protein blotting were purchased from Sigma). Protein was transferred by the semi-dry method (Bio-Rad) onto polyvinylidene difluoride membranes (Amersham) at $11 \mathrm{~V}$ for $50 \mathrm{~min}$. Blots were blocked for $1 \mathrm{~h}$ at room temperature with 5\% skimmed dry milk and probed with a 1:1,000 dilution of rabbit polyclonal connexin 43 antibody raised against the 252-271 fragment of the protein distant from the known sites of phosphorylation (31) for $1 \mathrm{~h}$ at room temperature. The connexin 43 antibody was a generous gift from Professors Bernard Himpens and Johan Vereecke, Laboratory of Physiology, KU Leuven, Belgium. Following extensive washes in phosphate-buffered saline PBS (pH 7.4) containing $0.1 \%$ Tween, the blot was incubated with alkaline phosphatase tagged anti-rabbit secondary antibody (Amersham) at a dilution of 1:10,000 for $1 \mathrm{~h}$ at room temperature. ECF ${ }^{\mathrm{TM}}$ substrate (Amersham) was added and the blots were quantitated with ImageQuant (Typhoon $^{\text {TM }} 9400$ Variable Mode Imager, Molecular Dynamics) as described above.

Electron microscopy. The animals were deeply anesthetised with diethyl-ether and perfused transcardially with $250 \mathrm{ml}$ of $0.1 \mathrm{M}$ PBS pH 7.4 followed by $300 \mathrm{ml}$ of fixative (1\% paraformaldehyde and $1 \%$ glutaraldehyde in phosphatebuffered solution, $\mathrm{pH}$ 7.4). Samples of the right parietal cortex were prepared for electron microscopy. Following thorough rinsing, the tissue blocks were incubated in an aqueous solution of $1 \% \mathrm{OsO}_{4}$ and $5 \% \mathrm{~K}_{2} \mathrm{Cr}_{4} \mathrm{O}_{7}$ (1:1). The samples were dehydrated then incubated in $1 \%$ uranyl-acetate and embedded in Durcupan epoxy resin (Fluka, Buchs, Switzerland). Semithin sections were cut on an ultramicrotome (Ultracut E, Reichert-Jung, Vienna, Austria) and stained on object glasses with a 1:1 mixture of $1 \%$ methylene blue and $1 \%$ azure II blue. The samples were then coverslipped with DPX mountant and analysed under a light microscope (Nikon E600, Nikon Co., Tokyo, Japan). Ultra-thin sections were cut of the same blocks and collected on 200-mesh copper grids. The preparations were then contrasted with $5 \%$ uranyl acetate and Reynolds lead citrate solution. Specimens were viewed under a Philips TM10 transmission electron microscope (Eindhoven, The Netherlands). Imaging was acquired with a computer-assisted digital camera (MegaView II, Soft Imaging Systems, Münster, Germany).

Approximately $900 \mu \mathrm{m}^{2}$ of sample surface was viewed systematically through all neocortical layers of the parietal cortex, and $12 \pm 2$ capillary cross sections were examined in each specimen. The total area of the so-called neurovascular unit, which consists of the capillary lumen, the surrounding endothelium and the astrocytic end-feet covering the basal lamina of the microvascular endothelium, was measured (Image Pro Plus 4.5 morphometric software; Media Cybernetics, Silver Spring, MD, USA).

Statistical analysis. Data are presented as the means \pm STDEV. Statistical analysis of the relative band densities and phosphorylation rates between the indicated groups were performed using the Student's t-test and the Newman-Keuls test. One-way analysis of variance (ANOVA) followed by the Bonferroni post hoc test was used when comparing astrocyte end-feet areas. SPSS 9.0 statistical software was used for analysis and $\mathrm{p}<0.05$ was considered statistically significant.

\section{Results}

Behavioural studies. The behavioural effects of the treatments on separate groups of animals were observed (Table I). The i.p. administration of 4-AP caused characteristic behavioural symptoms within $15 \mathrm{~min}$ : tremor of the vibrissal and masticatory muscles followed by a generalised tremor of the body musculature (detectable as a continuous fasciculation of the muscles), and then generalised tonic-clonic seizures (GTCS). The main behavioural symptoms disappeared after 90-120 min at most; the animals then displayed mild tremor or brief myoclonic episodes. By the end of the experiment, all the animals had recovered completely. Pre-treatment with MK-801 prevented the development of GTCS in $72.3 \%$ of the animals (Table II). The symptoms preceding GTCS (tremor of the vibrissae, tremor of the masticatory muscles, and generalised tremor) were not detected in animals pre-treated with MK-801. In these rats, instead of tremor, the first symptoms were hypotonia of the limbs and unsteady gait. Antagonist administered on its own did not induce any obvious behavioural changes.

Connexin 43 mRNA expression. The levels of GAPDH and connexin 43 mRNA were quantified in neocortex samples collected at 1, 3 and $24 \mathrm{~h}$ following 4-AP and the control physiological saline injections (not shown). In the controls as well as in the 4-AP treated animals, the GAPDH messages were not statistically different. Similarly, at no time were density changes observed in the normalised connexin 43 mRNA levels when the 4-AP treated group and the control group were compared (Fig. 1).

Connexin 43 protein phosphorylation. Previous studies have shown that the phosphorylated forms of connexin 43 migrate as separate bands on the gel during electrophoresis (9). These two phosphorylated forms, P1 and P2, migrated at $44 \mathrm{kDa}$ 
A

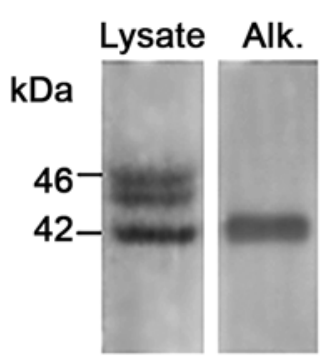

C

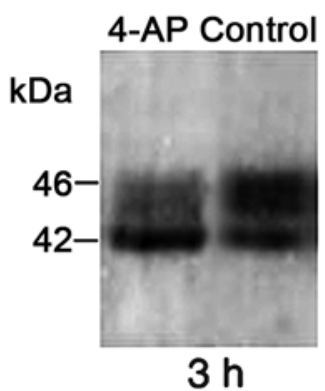

$\mathrm{E}$

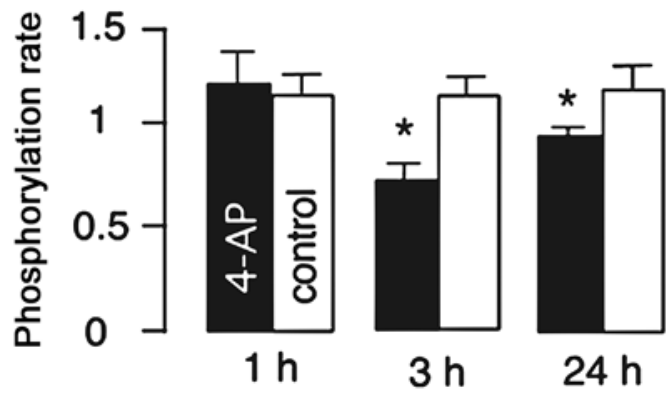

Figure 2. Expression of connexin 43 protein in the cerebral cortex following brief acute seizures. (A) Representative blots demonstrating the phosphorylation-dephosphorylation of connexin 43 isoforms. The P2 (46 kDa), P1 (44 kDa) and non-phosphorylated (NP, $42 \mathrm{kDa}$ ) forms were were detected in the control lysate (left), whereas only the NP form was present (right) following alkaline phosphatase treatment (Alk.). (B-D) Original blots demonstrating expression of the phosphorylated and non-phosphorylated forms of connexin 43 at 1 (B), 3 (C) and $24 \mathrm{~h}$ (D) following seizure induction. Dephosphorylation is visible at 3 and $24 \mathrm{~h}$ in convulsing animals (4-AP) compared to controls. (E) Summarised data of the changes in the phosphorylation of connexin 43 following seizures. Note the decrease in phosphorylation rate at $3 \mathrm{~h}$, which remains significant at $24 \mathrm{~h}$. 4-AP, convulsing animals; control, animals injected with saline; means \pm STDEV, $n=5, p=0.0017$ at $3 \mathrm{~h} ; \mathrm{p}<0.01$ at $24 \mathrm{~h}$.

and $46 \mathrm{kDa}$, respectively (Fig. 2A). Non-phosphorylated protein (NP) was detected at $42 \mathrm{kDa}$ (Fig. 2A). To confirm the phosphorylation status of the identified forms, parallel samples were treated with alkaline phosphatase. This resulted in the complete disappearance of the P1 and P2 bands, with a single band left representing the NP form (Fig. 2A). The complete insolubility of the $\mathrm{P} 2$ form and the partial insolubility of P1 in Triton X-100 have been reported (9) and were confirmed by our preliminary experiments (data not shown). Following the method of Christ et al (28), we successfully extracted both the phosphorylated and non-phosphorylated forms of connexin 43 without the use of detergents, achieving optimal protein yield (Fig. 2A). Some of the blots displayed P1 and P2 as a single fused band representing the overall quantity of phosphorylated connexin 43 , while in other blots the P1 and
A

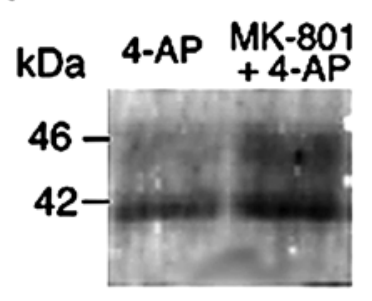

C

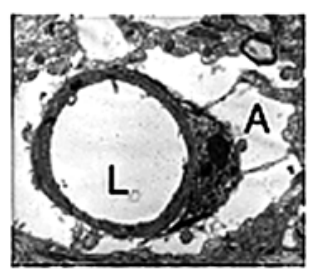

B

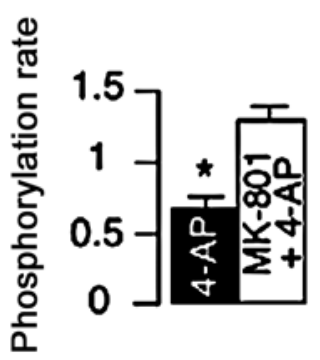

D

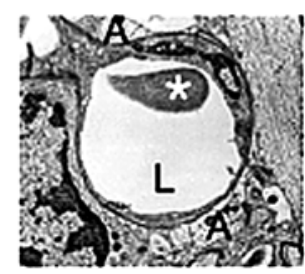

E

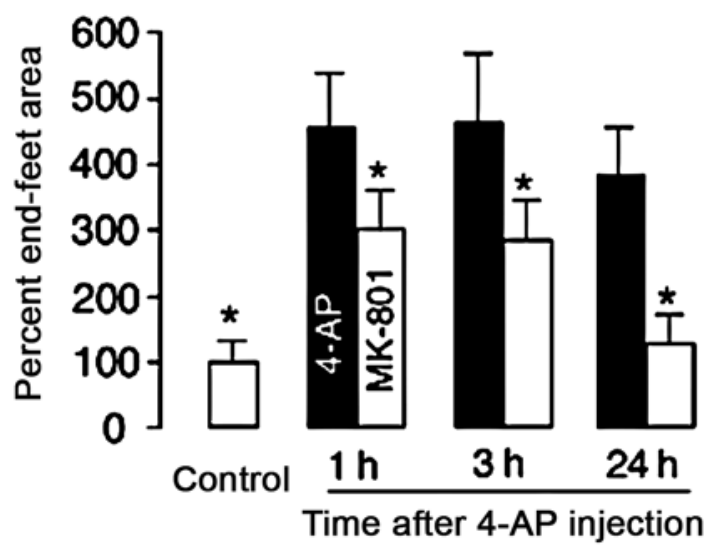

Figure 3. Connexin 43 dephosphorylation (A and B) and seizure-associated glial swelling (C and D) in the cerebral cortex can be reversed by MK-801 pre-treatment. (A) Representative blots showing the strong presence of phosphorylated connexin 43 after MK-801 pre-treatment $3 \mathrm{~h}$ following seizure induction. (B) Summarised data from panel A blots $(n=5 ; p<0.01)$. (C and D) Representative electron micrographs demonstrating perivascular glial swelling at $3 \mathrm{~h}$ post seizure induction (C), and reduced by MK-801 pretreatment (D). A, astrocyte end-feet; L, capillary lumen; asterisk, red blood cell. (E) Graph summarising percent changes in astrocytic end-feet area at 1, 3 and $24 \mathrm{~h}$ post 4 -AP injection. Note the prolonged swelling, significant at 1, 3 and $24 \mathrm{~h}$, and the protective effect of MK-801 (average \pm STDEV, $\mathrm{n}=27-33$; $\mathrm{p}<0.001)$.

P2 forms were visible as separate bands. Because of this slight discrepancy in migration properties, we were not able to analyse the P1 and P2 forms separately. Therefore, during densitometric analysis, P1 and P2 band densities were added together, and their sum was normalised to the density level of the NP band to determine the ratio of phosphorylated/nonphosphorylated connexin 43 molecules. The overall quantity of connexin 43 protein, expressed by the added density of all bands $(\mathrm{P} 1+\mathrm{P} 2+\mathrm{NP})$, showed no change in 4-AP treated tissue compared to the control neocortex (data not shown). The phosphorylation status of connexin 43 was unchanged at $1 \mathrm{~h}$ (Fig. 2B), but at $3 \mathrm{~h}$ (Fig. 2C) following 4-AP treatment there was an $\sim 50 \%$ decrease $(\mathrm{p}=0.0017$ ) in the ratio of phosphorylated versus non-phosphorylated connexin 43 forms in the epileptic animals. Surprisingly, this dephosphorylated status persisted until $24 \mathrm{~h}$ post seizure as a significant $\sim 10 \%$ reduction 
in phosphorylation (Fig 2D). To clarify the relation between NMDA receptor activation in 4-AP seizures and the subsequent phosphorylation changes of connexin 43, the NMDA antagonist MK-801 was applied prior to seizure induction. This pre-treatment resulted in a decrease in connexin 43 dephosphorylation at $3 \mathrm{~h}$ (Fig. 3A and B), suggesting that the long-lasting seizure effect was the result of an NMDAdependent mechanism.

Astrocyte end-feet area. In our next experiment, the area of perivascular astrocyte processes following 4-AP seizures with and without MK-801 pre-treatment was measured (Fig. 3C and D). Baseline values of the astrocytic end-feet area in untreated animals were considered to be $100 \%$ for the purposes of our analysis. A $464 \% \pm 85$ increase in the size of the end-feet compared to baseline was seen at $1 \mathrm{~h}$ following seizure induction, followed by a $471 \% \pm 104$ and $392 \% \pm 71$ increase in size at 3 and $24 \mathrm{~h}$, respectively $(\mathrm{n}=29-34, \mathrm{p}<0.001)$. Swelling was abolished by the application of MK-801 with $310 \% \pm 59$, $292 \% \pm 59$ and $129 \% \pm 45$ end-feet areas in the 1,3 , and $24 \mathrm{~h}$ groups, respectively $(\mathrm{n}=28-32, \mathrm{p}<0.001)$ (Fig. 3E).

\section{Discussion}

The present study is the first to demonstrate the posttranslational changes of the GJ subunit connexin 43 in vivo in epileptic animals. Our results strongly indicate that, in acute GTCS, connexin 43 is not regulated at the transcriptional level. The expression of connexin mRNA in our neocortical samples was very stable in every animal group. On the other hand, very important phosphorylation changes were observed that were dependent on regulation processes mediated by NMDA glutamate receptors. Several lines of evidence suggest a regulatory role for connexin 43 in adjusting extracellular space homeostasis by modulating intercellular communication between CNS glial cells. Conditional knockout mice lacking connexin 43 show a slowed decay of $\left[\mathrm{K}_{\mathrm{o}}^{+}\right]$subsequent to stimulus train (32), indicating that astrocytic GJ facilitate intercellular $\mathrm{K}^{+}$diffusion. A likely mechanism is that open GJ contribute low-resistance intercellular coupling between neighbouring cells (33), allowing the passive movement of all particles under $1 \mathrm{kDa}(17)$. Therefore, GJs facilitate the redistribution and buffering of several ions and molecules accumulated during GTCS, such as $\mathrm{K}^{+}(32,34)$ or glutamate (35), via this cellular network. This has been referred to as 'spatial buffering' (18).

A decreased phosphorylation rate in the GJ subunit connexin 43 was observed in response to seizures, which corresponds to previous findings in astrocyte cultures. The dephosphorylation of connexin 43 has been observed in response to various pathological stimuli in vitro $(19,36,37)$, for example when reconstituting a seizure-like environment with excess glutamate $(1 \mathrm{mM})$ and high $\left[\mathrm{K}^{+}\right]_{\mathrm{o}}(15 \mathrm{mM})$ in brain slices (19). This dephosphorylation was demonstrated to correspond with a reduction in intercellular coupling $(16,38)$. Similar responses were observed using in vitro models of ischemia and metabolic inhibition $(37,39)$.

Our experiments also indicate that MK-801 attenuates the symptoms of seizures. Pre-treatment prevented the onset of GTCS in more than $70 \%$ of the animals. MK- 801 is a high- affinity open-channel blocker that blocks the ion channel of the receptor at the NMDA receptor, inhibiting or decreasing the ion fluxes which follow glutamate binding (40). MK-801 administration i.p. and i.c.v. was found to protect against 4-AP seizures in electrophysiological experiments (41). The present experiments provide further data on the important role of glutamate and NMDA receptors in seizure pathology, and prove that the blockage of NMDA receptor is beneficial and decreases glial swelling significantly. These results also increase the possibility of therapeutic applications of NMDAreceptor antagonists for seizure-related brain edema.

The role of the phosphorylation status of connexin 43 in the regulation of GJ permeability has been studied extensively. The balance between the two states is set by the equilibrium between the phosphatase PP-2B/calcineurin (38) and the kinase c-Src (16). Both enzymes are regulated by intracellular $\mathrm{Ca}^{2+}$ levels. As NMDA receptors permit the influx of $\mathrm{Ca}^{2+}$, it is possible that the activation of this receptor is related to connexin 43 dephosphorylation through the activation of phosphatase PP-2B/calcineurin. Cytoplasmic $\mathrm{Ca}^{2+}$ may, in response to mGluR stimulation of acute hippocampal slices, be increased by other mechanisms, such as the release from internal stores reported by Potter and McCarthy (42). It may enter the cell via voltage-sensitive channels (43) and metabotropic glutamate receptors during A-4P seizures as assessed by in vivo two-photon microscopy (44). NMDA receptors are known to be expressed in neurons (45), while astrocytes react to glutamate by metabotropic receptors and express NMDA subunits only under pathological conditions such as ischemia or anoxia (46). In contrast, recent studies have clearly demonstrated the presence of functional NMDA subunits in cortical astrocytes in the normal brain $(47,48)$.

MK-801 preserved connexin 43 phosphorylation in glutamate-treated astrocyte cultures (19). Our results show a similar effect in vivo; the blockage of NMDA glutamate receptors by MK-801 inhibited connexin 43 dephosphorylation in astrocytes and, at the same time, significantly reduced cellular swelling. We therefore believe that MK-801 acted not only on neuronal, but also on astrocytic NMDA receptors in our experiments. Consequently, NMDA receptor activation could potentially regulate gap junction coupling in astrocytes by modulating intracellular $\mathrm{Ca}^{2+}$ levels.

Our electron microscopy measurements demonstrate prolonged perivascular astrocytic swelling, which was simultaneous to the impairment of GJ coupling (connexin 43 dephosphorylation). This implies that the latter contributes to seizure-related glial edema. Astrocyte swelling appeared earlier than connexin dephosphorylation, but after $3 \mathrm{~h}$ its decrease followed the decrease of dephosphorylation. On the other hand, MK-801 decreased swelling at every time point, implying that it was largely caused by excessive glutamate release. This long-lasting (150 min from the injection of 4-AP) significant elevation of extracellular glutamate has been proven by our previous experiments in 4-AP seizures (22). Therefore, we believe that glial swelling in GTCS has two phases: Phase 1 depends on elevated extracellular glutamate and causes swelling through the entry of $\mathrm{Na}^{+}$and $\mathrm{Ca}^{2+}$ into the cell (42), and Phase 2 (post-3 h) is mediated by the opening of the hemichannels through the dephosphorylation process and the uncoupling of the astrocytes $(15,39)$. This second phase might 
be responsible for the decrease in ADC values at $24 \mathrm{~h}$ (4). GJ proteins may exist as hemichannels, and have been shown to respond to dephosphorylation with increased permeability. As such, they provide a new route for solute trafficking between the extra- and intracellular compartments (39). As the density of hemichannels on the cell surface is not known, we cannot estimate their contribution to astrocyte swelling in seizures. Our results suggest that, in addition to other known factors (e.g., aquaporins) (49) GJ and glutamate-dependent mechanisms contribute significantly to the phases of seizurerelated glial cell swelling.

In the present study, we demonstrated the dephosphorylation of the GJ protein connexin 43 following seizures. Our results indicate that the swelling of astrocytes and connexin dephosphorylation are related phenomena. Based on previous in vitro data, we propose that connexin 43 dephosphorylation results in the closure of intercellular GJs, which in turn isolates individual astrocytes. This mechanism may inhibit spatial buffering and contributes to long-lasting astrocyte swelling in seizure. The inhibition of astrocytic swelling and the simultaneous prevention of connexin dephosphorylation by MK-801 indicates an NMDA receptor-dependent regulatory mechanism at work in the rat neocortex. These observations may open up a new therapeutic avenue for re-establishing the spatial buffering of the astrocyte network and for helping in the recovery of brain tissue following epileptic events.

\section{Acknowledgements}

We would like to thank Professors B. Himpens and J. Vreecke at Katholieke Universiteit (KU) Leuven, Belgium for generously providing the connexin 43 antibody. This study was supported by a grant from the Gedeon Richter Centennial Foundation (Budapest, Hungary), and by the Hungarian National Office for Research and Technology (NKTH/RET 2004/08).

\section{References}

1. Heinemann U: Excitatory amino acids and epilepsy-induced changes in extracellular space size. Adv Exp Med Biol 203: 449-460, 1986.

2. Woodbury DM, Engstrom FL, White HS, Chen CF, Kemp JW and Chow SY: Ionic and acid-base regulation of neurons and glia during seizures. Ann Neurol 16 (Suppl): S135-S144, 1984.

3. Sykova E: Glia and volume transmission during physiological and pathological states. J Neural Transm 112: 137-147, 2005.

4. Fabene PF, Weiczner R, Marzola P, et al: Structural and functional MRI following 4-aminopyridine-induced seizures: a comparative imaging and anatomical study. Neurobiol Dis 21: 80-89, 2006.

5. Nakase T, Sohl G, Theis M, Willecke K and Naus CC: Increased apoptosis and inflammation after focal brain ischemia in mice lacking connexin43 in astrocytes. Am J Pathol 164: 2067-2075, 2004.

6. Rouach N, Avignone E, Meme W, et al: Gap junctions and connexin expression in the normal and pathological central nervous system. Biol Cell 94: 457-475, 2002.

7. Nemani VM and Binder DK: Emerging role of gap junctions in epilepsy. Histol Histopathol 20: 253-259, 2005.

8. Nadarajah B, Thomaidou D, Evans WH and Parnavelas JG: Gap junctions in the adult cerebral cortex: regional differences in their distribution and cellular expression of connexins. J Comp Neurol 376: 326-342, 1996.

9. Musil LS and Goodenough DA: Biochemical analysis of connexin43 intracellular transport, phosphorylation, and assembly into gap junctional plaques. J Cell Biol 115: 1357-1374, 1991.

10. Martin PE and Evans WH: Incorporation of connexins into plasma membranes and gap junctions. Cardiovasc Res 62: 378-387, 2004.
11. Willecke K, Eiberger J, Degen J, et al: Structural and functional diversity of connexin genes in the mouse and human genome. Biol Chem 383: 725-737, 2002.

12. Rash JE, Yasumura T, Dudek FE and Nagy JI: Cell-specific expression of connexins and evidence of restricted gap junctional coupling between glial cells and between neurons. J Neurosci 21: 1983-2000, 2001.

13. Condorelli DF, Trovato-Salinaro A, Mudo G, Mirone MB and Belluardo N: Cellular expression of connexins in the rat brain: neuronal localization, effects of kainate-induced seizures and expression in apoptotic neuronal cells. Eur J Neurosci 18: 1807-1827, 2003.

14. De Sousa PA, Valdimarsson G, Nicholson BJ and Kidder GM: Connexin trafficking and the control of gap junction assembly in mouse preimplantation embryos. Development 117: 1355-1367, 1993.

15. Saez JC, Contreras JE, Bukauskas FF, Retamal MA and Bennett MV: Gap junction hemichannels in astrocytes of the CNS. Acta Physiol Scand 179: 9-22, 2003.

16. Toyofuku T, Akamatsu Y, Zhang H, Kuzuya T, Tada M and Hori M: c-Src regulates the interaction between connexin-43 and ZO-1 in cardiac myocytes. J Biol Chem 276: 1780-1788, 2001.

17. Simpson I, Rose B and Loewenstein WR: Size limit of molecules permeating the junctional membrane channels. Science 195: 294-296, 1977.

18. Simard M and Nedergaard M: The neurobiology of glia in the context of water and ion homeostasis. Neuroscience 129: 877-896, 2004.

19. Nagy JI and Li WE: A brain slice model for in vitro analyses of astrocytic gap junction and connexin43 regulation: actions of ischemia, glutamate and elevated potassium. Eur J Neurosci 12: 4567-4572, 2000

20. Schneider GH, Baethmann A and Kempski O: Mechanisms of glial swelling induced by glutamate. Can J Physiol Pharmacol 70 (Suppl): S334-S343, 1992.

21. $\mathrm{Su} \mathrm{G}$, Kintner DB and Sun D: Contribution of $\mathrm{Na}(+)-\mathrm{K}(+)-\mathrm{Cl}(-)$ cotransporter to high- $[\mathrm{K}(+)](\mathrm{o})$ - induced swelling and EAA release in astrocytes. Am J Physiol Cell Physiol 282: C1136-C1146, 2002.

22. Kovacs A, Mihaly A, Komaromi A, et al: Seizure, neurotransmitter release, and gene expression are closely related in the striatum of 4-aminopyridine-treated rats. Epilepsy Res 55: 117-129, 2003.

23. Szakács R, Weiczner R, Mihály A, Krisztin-Péva B, Zádor Z and Zádor E: Non-competitive NMDA receptor antagonists moderate seizure-induced c-fos expression in the rat cerebral cortex. Brain Res Bull 59: 485-493, 2003.

24. Mihály A, Bencsik K and Solymosi T: Naltrexone potentiates 4-aminopyridine seizures in the rat. J Neural Transm Gen Sect 79: 59-67, 1990.

25. Chomczynski $P$ and Sacchi N: Single-step method of RNA isolation by acid guanidinium thiocyanate-phenol-chloroform extraction. Anal Biochem 162: 156-159, 1987.

26. Zádor E, Mendler L, ver Heyen M, Dux L and Wuytack F: Changes in mRNA levels of the sarcoplasmic/endoplasmicreticulum $\mathrm{Ca}(2+)$-ATPase isoforms in the rat soleus muscle regenerating from notexin-induced necrosis. Biochem J 320: 107-113, 1996.

27. Mihály A, Borbély S, Világi I, et al: Neocortical c-fos mRNA transcription in repeated, brief, acute seizures: is c-fos a coincidence detector? Int J Mol Med 15: 481-486, 2005.

28. Christ GJ, Day NS, Day M, et al: Increased connexin43-mediated intercellular communication in a rat model of bladder overactivity in vivo. Am J Physiol Regul Integr Comp Physiol 284: R1241-R1248, 2003.

29. Fort P, Marty L, Piechaczyk M, et al: Various rat adult tissues express only one major mRNA species from the glyceraldehyde-3phosphate-dehydrogenase multigenic family. Nucleic Acids Res 13: 1431-1442, 1985.

30. Wang Y, Mehta PP and Rose B: Inhibition of glycosylation induces formation of open connexin- 43 cell-to-cell channels and phosphorylation and triton X-100 insolubility of connexin-43. J Biol Chem 270: 26581-26585, 1995.

31. Malfait M, Gomez P, van Veen TA, et al: Effects of hyperglycemia and protein kinase $\mathrm{C}$ on connexin43 expression in cultured rat retinal pigment epithelial cells. J Mem Biol 181: 31-40, 2001.

32. Wallraff A, Kohling R, Heinemann U, Theis M, Willecke K and Steinhauser C: The impact of astrocytic gap junctional coupling on potassium buffering in the hippocampus. J Neurosci 26 : 5438-5447, 2006. 
33. Flagg-Newton J, Simpson I and Loewenstein WR: Permeability of the cell-to-cell membrane channels in mammalian cell juncton. Science 205: 404-407, 1979.

34. Walz W, Klimaszewski A and Paterson IA: Glial swelling in ischemia: a hypothesis. Dev Neurosci 15: 216-225, 1993.

35. Goldberg GS, Valiunas V and Brink PR: Selective permeability of gap junction channels. Biochim Biophys Acta 1662: 96-101, 2004.

36. Li WE, Ochalski PA, Hertzberg EL and Nagy JI: Immunorecognition, ultrastructure and phosphorylation status of astrocytic gap junctions and connexin43 in rat brain after cerebral focal ischaemia. Eur J Neurosci 10: 2444-2463, 1998.

37. Li W, Hertzberg EL and Spray DC: Regulation of connexin43protein binding in astrocytes in response to chemical ischemia/ hypoxia. J Biol Chem 280: 7941-7948, 2005.

38. Li WE and Nagy JI: Connexin43 phosphorylation state and intercellular communication in cultured astrocytes following hypoxia and protein phosphatase inhibition. Eur J Neurosci 12: 2644-2650, 2000.

39. Contreras JE, Sáez JC, Bukauskas FF and Bennett MV: Gating and regulation of connexin $43(\mathrm{Cx} 43)$ hemichannels. Proc Natl Acad Sci USA 100: 11388-11393, 2003.

40. Chapman AG: Glutamate receptors in epilepsy. Prog Brain Res 116: 371-383, 1998.

41. Morales-Villagran A, Urena-Guerrero ME and Tapia R: Protection by NMDA receptor antagonists against seizures induced by intracerebral administration of 4-aminopyridine. Eur J Pharmacol 305: $87-93,1996$.
42. Porter JT and McCarthy KD: Hippocampal astrocytes in situ respond to glutamate released from synaptic terminals. J Neurosci 16: 5073-5081, 1996

43. White HS, Skeen GA and Edwards JA: Pharmacological regulation of astrocytic calcium channels: implications for the treatment of seizure disorders. Prog Brain Res 94: 77-87, 1992.

44. Tian GF, Azmi H, Takano T, et al: An astrocytic basis of epilepsy. Nat Med 11: 973-981, 2005.

45. Curras-Collazo MC, Chin C, Diaz G, Stivers C, Bozzetti L and Tran LY: Immunolabeling reveals cellular localization of the Nmethyl-D-aspartate receptor subunit NR2B in neurosecretory cells but not astrocytes of the rat magnocellular nuclei. J Comp Neurol 427: 93-108, 2000

46. Gottlieb $M$ and Matute C: Expression of ionotropic glutamate receptor subunits in glial cells of the hippocampal CA1 area following transient forebrain ischemia. J Cereb Blood Flow Metab 17: 290-300, 1997.

47. Krebs C, Fernandes HB, Sheldon C, Raymond LA and Baimbridge KG: Functional NMDA receptor subtype $2 \mathrm{~B}$ is expressed in astrocytes after ischemia in vivo and anoxia in vitro. J Neurosci 23: 3364-3372, 2003.

48. Schipke CG, Ohlemeyer C, Matyash M, Nolte C, Kettenmann H and Kirchhoff F: Astrocytes of the mouse neocortex express functional N-methyl-D-aspartate receptors. FASEB J 15: 1270-1272, 2001.

49. Binder DK, Papadopoulos MC, Haggie PM and Verkman AS: In vivo measurement of brain extracellular space diffusion by cortical surface photobleaching. J Neurosci 24: 8049-8056, 2004. 